\title{
AIP Mutation Causing Familial Pituitary Tumours
}

\section{Cordiner R, McManus F, Hughes K, Boyle J, Panarelli M, Drummond R, Carty D \\ Department of Diabetes, Endocrinology and Clinical Pharmacology \\ Glasgow Royal Infirmary}

\section{Background}

Familial isolated pituitary adenoma (FIPA) is an increasingly recognised cause of familial pituitary tumours with autosomal dominant inheritance. An increased population risk of AIP mutations has recently been reported in Northern Ireland ${ }^{1}$.

We present the cases of three siblings, with likely AIP related disease, attending different endocrinology clinics in Glasgow.

\section{Patient 1}

Patient 1 was referred, aged 47, with bitemporal hemianopia (Image B). Initial bloods demonstrated pan hypopituitarism with a prolactin of 199,490 mlU/l. MRI revealed a giant macroadenoma with suprasellar extension and secondary hydrocephalus (Image A). He was transferred to neurosurgery, but was managed medically. He remains on high-dose cabergoline 2 grams weekly, and full pituitary hormone replacement. Further imaging has shown a substantial reduction in tumour bulk (Image C).
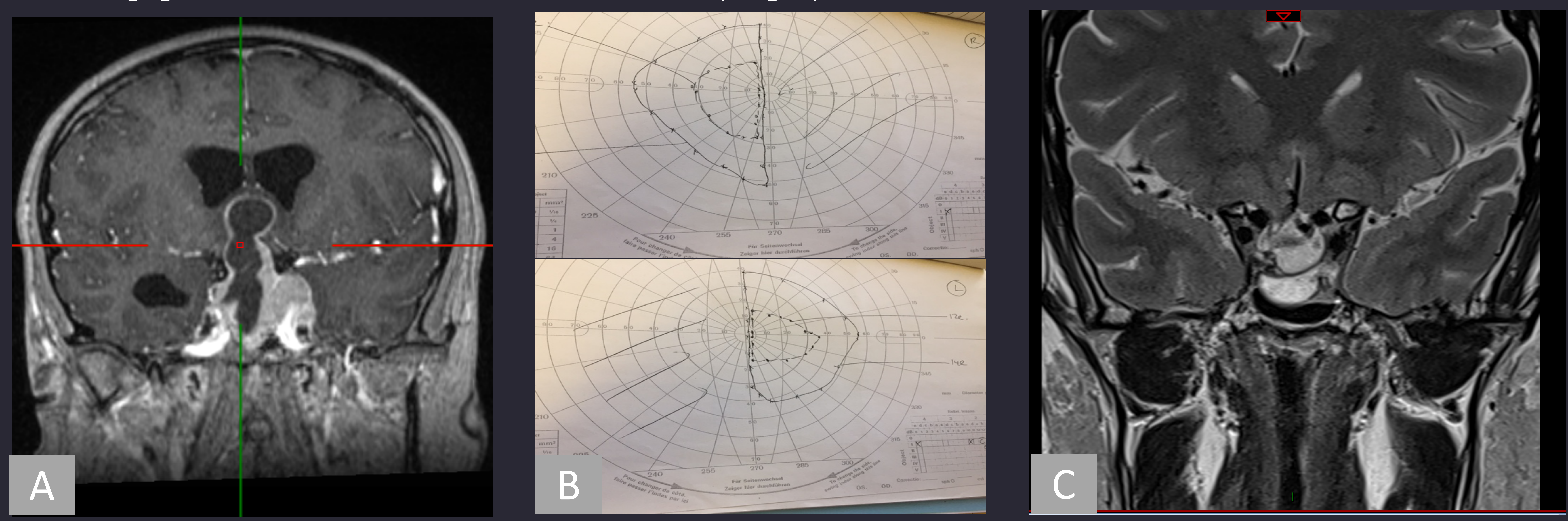

Patient 2

Patient 2 was referred, aged 44. She has anxiety, treated with risperidone and paroxetine. She presented with secondary amenorrhoea. Prolactin $3000 \mathrm{mlU} / \mathrm{l}$, remaining elevated following withdrawal of psychotropic medication. Pituitary function was otherwise normal. She was unable to tolerate MRI, but $\mathrm{CT}$ has shown an $8 \mathrm{~mm}$ lesion. Imaging and prolactin levels have remained static with cabergoline $2 \mathrm{~g} /$ week

\section{Patient 3}

Patient 3 was referred, aged 46. She also has anxiety and presented with galactorrhoea and secondary amenorrhoea.

Prolactin was $4437 \mathrm{mlU} / \mathrm{l}$, and remained elevated following withdrawal of citalopram. Pituitary function was otherwise normal.

MRI showed two microadeomas: $9 \mathrm{~mm}$ and $7.5 \mathrm{~mm}$. Cabergoline was initiated, however, compliance with treatment has been intermittent between 2007 - 2016, with recurrent galactorrhoea on cessation. Claustrophobia has made further imaging intolerable.

Patient 3 mentioned her siblings were also attending clinics with pituitary adenomas, and subsequently tested positive for AIP mutation.

\section{AIP-Mutated Familial Isolated Pituitary Adenoma}

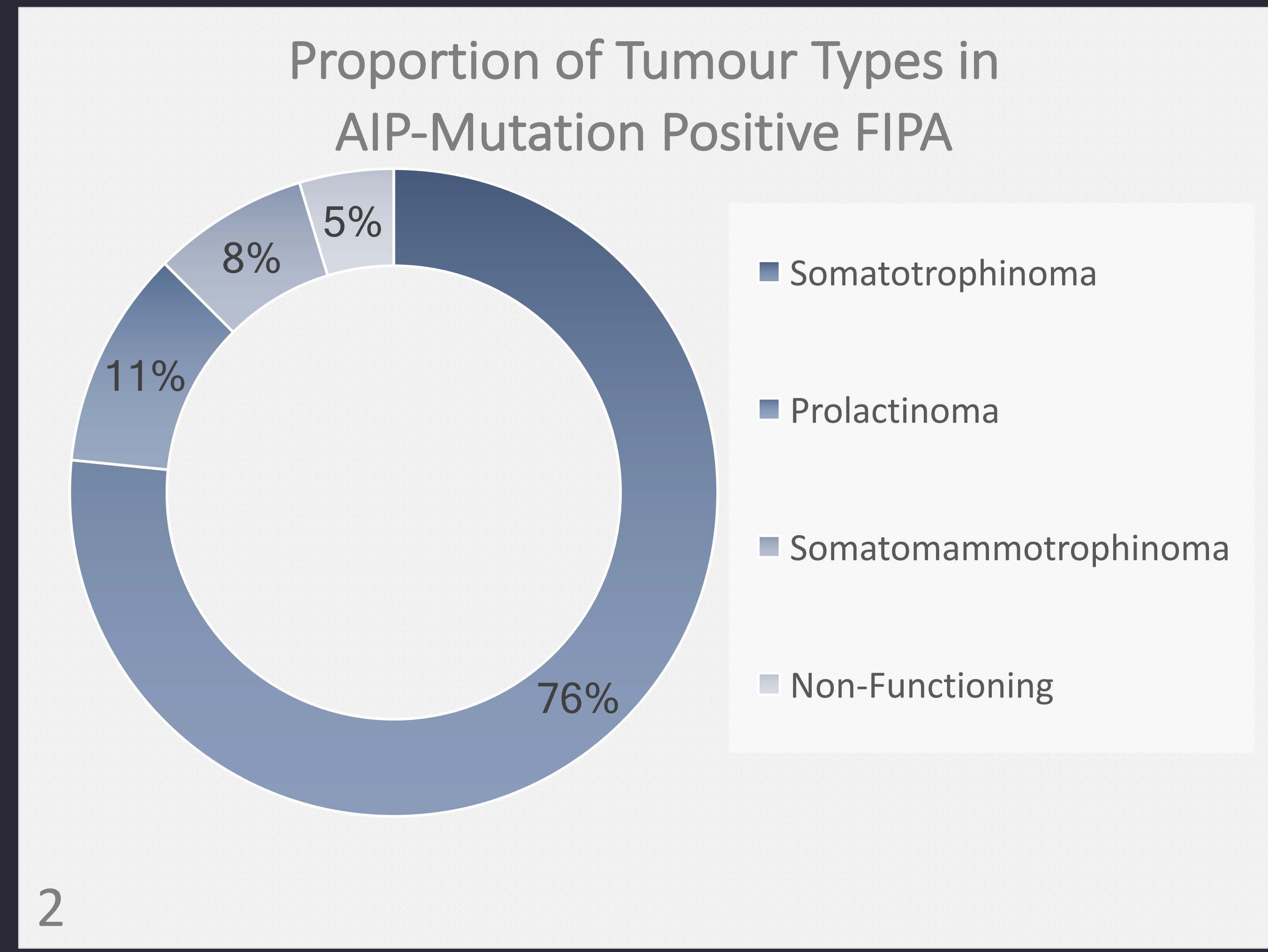

\footnotetext{
- AIP mutation present in $15-20 \%$ of FIPA

- Autosomal Dominant

- Penetrance 12.5 - 30\%

- Onset between $2^{\text {nd }}$ and $3^{\text {rd }}$ decade

- Tend towards larger, more aggressive tumours

- Greater risk of apoplexy

- Respond less well to somatostatin analogues

- More likely to require radiotherapy

- Poor control of IGF-1 with pegvisomant in somatostatinomas
}

\section{Conclusion}

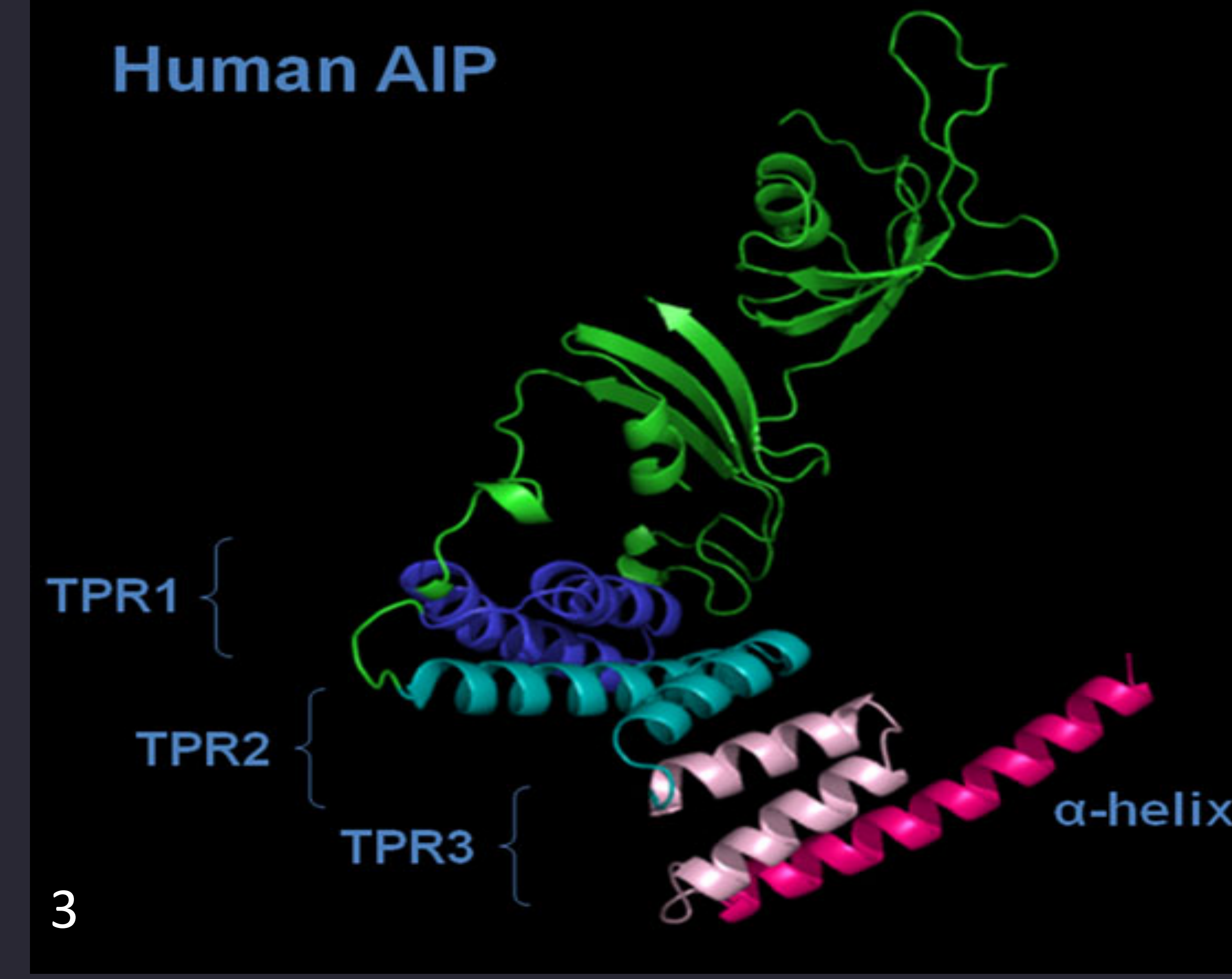

This family demonstrates three siblings with prolactinomas, and no other family history of endocrinoppathy. As patient 3 has tested positive for AIP mutation, they been referred for genetic screening and counselling. These cases demonstrate the importance of obtaining an accurate family history and appropriate clinical and biochemical assessment of the index patient. Current data support the testing of AIP mutations in patients presenting with pituitary tumours at a young age, or with a family history of pituitary disease.

References

1. Harvinder S et al, AIP Mutation in Pituitary Adenomas in the $18^{\text {th }}$ Century, NEJM, 2011

2. Korbonits et al, AIP-Related Familial Isolated Pituitary Adenomas, GeneReviews, 2012

3. Image reference FIPA Patients Society 2017 